\title{
Relations Among Personal Agency, Motivation, and School Adjustment in Early Adolescence
}

\author{
Theodore A. Walls \\ University of Rhode Island
}

Todd D. Little
University of Kansas

\begin{abstract}
The authors examined relations among motivational styles and school adjustment in a sample of 786 th and 8th grade U.S. students. Specifically, the authors tested the hypothesis that agency beliefs mediate relations between styles of motivational self-regulation (i.e., intrinsic, identified, introjected, and extrinsic) and school adjustment (school grades, school well-being, and positive and negative affect). A structural equation model testing this hypothesis indicated that agency beliefs about one's effort mediate the relations between the styles and positive school adjustment. By contrast, the extrinsic style was not mediated by agency beliefs but reflected adverse low-magnitude direct effects on all of the outcomes except positive affect. Overall, the model strongly predicted school adjustment, and adherence to the identified motivational style was particularly important.
\end{abstract}

The relations between motivation and school-related outcomes such as academic performance and academic well-being have been routinely established in the educational literature (Deci \& Ryan, 2000; Ryan \& Connell, 1989; Wentzel, Weinberger, Ford, \& Feldman, 1990). Likewise, the strong influence of various dimensions of perceived control on school-related outcomes has been well researched and documented (Skinner, Wellborn, \& Connell, 1990; Skinner, Zimmer-Gembeck, \& Connell, 1998). However, numerous researchers have noted the surprising lack of studies that examine the linkages among motivational factors and perceptions of control (Eccles, Lord, \& Roeser, 1996; Ford, 1992; Little, 1998, 2002; Stipek, 1996; Wentzel et al., 1990). Recent theoretical work has focused on the need for systemic, multidimensional characterizations of the motivational and control-based constructs that encompass goal-directed activities (Brandtstädter, 1998; Chapman, 1984; Ford, 1992; Lerner \& Walls, 1999; Little, Hawley, Henrich, \& Marsland, 2002; Ryan \& Deci, 2000; Schunk, 1991; Skinner, 1996; Skinner, Chapman, \& Baltes, 1988; Weiner, 1985, 1995; Weiner \& Kukla, 1970). In this study, we take a first step toward addressing this need. We based our study design on the actioncontrol theory model of perceived control (e.g., Little, 1998, 2002; Skinner et al., 1988) and the self-determination theory model of motivation (Deci \& Ryan, 2000) as a joint theoretical foundation.

This study is based on Theodore A. Walls's doctoral dissertation, conducted under the supervision of Penny Hauser-Cram in the Lynch Graduate School of Education at Boston College and under the auspices of the Agency in Development Project (Todd D. Little, Director) at Yale University. The study was supported in part by a grant from Yale College of Yale University. We wish to acknowledge the contributions of the dissertation committee, the members of the Agency in Development laboratory, and the members of the school community who participated in the study.

Correspondence concerning this article should be addressed to Theodore A. Walls, Department of Psychology, University of Rhode Island, 2 Chafee Road, Kingston, RI 02881, or to Todd D. Little, Department of Psychology, University of Kansas, 1455 Jayhawk Boulevard, Lawrence, KS 66045. E-mail: walls@uri.edu or yhat@ku.edu
In self-determination theory, self-regulatory beliefs about motivation arise from the diverse ways in which social values and external contingencies are progressively transformed into personal values and self-motivations (Ryan \& Deci, 2000). Selfdetermination theory contends that individuals have a psychological need for autonomous actions (i.e., to freely choose what they will engage in) and that different styles of action motivation can be placed along a continuum. Deci and Ryan (2000) suggested that at one end of this motivational self-regulation continuum reside behaviors that are intrinsically motivated. Students who are intrinsically motivated exhibit an inherent joy and satisfaction in exercising one's capabilities to explore and learn (Ryan \& Deci, 2000). Moving along the continuum, four additional motivational selfregulatory styles have been described: (a) in integrated regulation, the goal and its pursuit have been fully incorporated (i.e., integrated) into the self and are in congruence with personal values and needs; (b) in identified regulation, goals are readily adopted and they are seen as personally important, but they are not fully owned; (c) in introjected regulation, regulatory behaviors are adopted only nominally and are not readily endorsed; and finally, (d) in external or extrinsic regulation, behaviors proceed purely for the receipt of a reward or in response to some other external pressure (e.g., a parent's desire or a teacher's demand).

Studies have consistently shown that extrinsic regulation is negatively associated with well-being and that intrinsic regulation frequently promotes mental health and positive life experiences (Ryan \& Connell, 1989; Ryan, Sheldon, Kasser, \& Deci, 1996). These studies indicate that identified regulation is associated with positive affective states and life experiences, whereas introjected regulation is generally negatively associated with these outcomes. Consistently, recent findings by Koestner and Losier (2002) have shown that identified regulation is associated with a diversity of educational advancement indicators and positive educational beliefs, whereas introjected regulation is associated with detrimental indicators. Their work suggests that the relative benefit of intrinsic motivation in promoting positive adaptation in the educational domain is lower than that of identified motivation. Finally, complementary work by Covington and colleagues (Covington \& 
Müeller, 2001; Elliot \& Covington, 2001) suggests that intrinsically motivated students may navigate a world that is full of extrinsic rewards in different ways when task engagement is involved.

Action-control beliefs are views about competencies and the potential means perceived to be at one's disposal for the pursuit of a particular goal (Little, 1998; Little \& Lopez, 1996; Skinner et al., 1988). These beliefs are considered in light of the broader perspective on human agency in which the individual is seen as volitional, intentional, and self-referencing. The individual is also the key participant in identifying, selecting, and pursuing one's goals (Boesch, 1991; Brandtstädter, 1998; Little, 1998; Skinner, 1995). Action-control beliefs are composed of three key belief components: (a) means-ends beliefs about the relevance of various means (e.g., effort, ability, teachers) for achieving the ends of a given goal, (b) agency beliefs about whether these means are personally accessible and usable in pursuing a goal, and (c) control-expectancy beliefs that reflect a general assessment of the attainability of the goal. Research has shown that among all of these beliefs, agency beliefs about effort and ability in achieving academic success are the strongest and most critical predictors of actual school performance (Little, Lopez, Oettingen, \& Baltes, 2001; Little, Oettingen, Stetsenko, \& Baltes, 1995; Skinner, 1990; Stetsenko, Little, Oettingen, \& Baltes, 1995). High agency beliefs are also associated with lower anxiety in elementary school children and positively related to positive attitudes and self-esteem in adolescence (Grob, Little, Wanner, Wearing, \& EURONET, 1996; Little \& Lopez, 1996). Agency beliefs are highly comparable with several other constructs used in the study of perceived control, including, but not limited to, Bandura's (1977) self-efficacy. For an extensive review of perceived control constructs, see Skinner (1996).

Both action-control theory and self-determination theory share the fundamental assumption of the person as an active, goaloriented, and self-regulating organism (Little, Hawley, et al., 2002). However, the extent to which one is motivated to pursue a goal versus the extent to which one is aware of the actions needed for its pursuit need not be logically interdependent. For example, in order to quit smoking, one may be completely aware of the means needed to quit and even believe that one possesses such means. As a completely separate matter, however, one may have no motivation to quit smoking. On the other hand, change in one's beliefs about the accessibility of means to quit smoking, such as the availability of medication or social support, may increase one's motivation to pursue a goal, or conversely, an increase in motivation to quit may result in new efforts to attain needed means. An example related to the school context is the student who has extremely high ability and wherewithal to expend effort, ample resources, and clear understanding of what is needed for academic performance yet who chooses not to invest himself or herself in school-related activities. An understanding of the interrelationships of these two constructs in any given domain of activity, therefore, is critical to the explication of an underlying belief system that drives action (Little, Hawley, et al., 2002; Ryan et al., 1996; Walls, 2002).

Although no studies have jointly considered these to two predictors in the same sample, relevant theory strongly supports the argument for placing agency in a mediational position between the motivational self-regulation styles and school adjustment outcomes. For example, Kuhl (1982) argued for a systemic process that requires the cognitive regulation of a motivational tendency that gives rise to an intention to act. Similarly, Heckhausen, Schmalt, and Schneider (1979) argued that mediating processes such as intentions and actions likely cause further variation on outcomes in experiments after state orientations such as motivation or learned helplessness are considered. Dweck (1986) argued that cognitive mediators of motivation likely allow students to construe a situation, interpret events in the situation, and process information about the situation; agency beliefs provide one such mediator. Finally, related work by Wentzel and colleagues (1990) casts the effects of self-restraint and other control-related factors as subservant to the effects of motivation. In addition, we contend that motivational states are more global in their influence on school adjustment, whereas action-control beliefs are more proximal to school adjustment. Although we advocate this conceptual ordering as the most theoretically viable and compatible with current findings (Little et al., 2001), alternative orderings of the constructs may be supported theoretically and quantitatively, and we discuss these possibilities in drawing our conclusions. In addition, other theoretical perspectives such as Weiner's $(1985,1995)$ offer models about attributional locus giving rise to motivation to act. Here, however, motivation is more closely linked to the intention phase of an action sequence.

The central goal of this study is to examine the interplay between motivational styles, agency beliefs, and how one calls on them to regulate academic actions related to school adjustment. Recent findings have suggested that specific belief components within the agency and motivation constructs are particularly predictive of positive outcomes in middle school (Little, 1998; Ryan \& Connell, 1989). Moreover, previous studies have indicated that components of motivational and agentic views are well differentiated in early adolescence and may be particularly salient in predicting middle school performance outcomes (Gottfried, 1985; Gottfried, Fleming, \& Gottfried, 2001; Roeser, Eccles, \& Sameroff, 1998; Stetsenko et al., 1995). In addition, numerous studies indicate that perceived control and motivational style may be related to affective states in school (Patrick, Skinner, \& Connell, 1993; Weiner, 1985). Our study extends this work to the relations between the two complementary constructs, agency and motivation, to determine how they function together as a motive-control belief system to influence school adjustment. We think of school adjustment as a meta-level construct encompassing a range of specific components that together constitute favorable school functioning. In order to create a robust profile of school adjustment, we selected school performance (grades), positive and negative affect, and self-reported school well-being as outcome measures (Diener, 1984; Harter, 1988a).

\section{Hypotheses}

Our primary hypothesis was that agency beliefs would mediate the effects of motivational self-regulation on the various school adjustment outcome measures. In terms of more specific hypotheses, we expected that identified motivation would have greater influence (via agency beliefs) on the school adjustment outcomes than the other styles. We also anticipated that intrinsic selfregulation would be associated with school well-being and positive affect but not necessarily with school grades. We expected introjected and extrinsic motivation to relate to school adjustment 
outcomes negatively. We also expected that of the two agency beliefs, effort would have greater influence on the outcomes. Further, we expected these effects to be present even when controlling for gender, intellective skill, resource class participation, and ethnicity. In general, our hypotheses targeted identification of the strongest and most meaningful relations with school adjustment outcomes.

\section{Method}

\section{Participants}

Data reported here are cross-sectional and from a larger study that assessed approximately 1,500 students in sixth through ninth grade. For this study, we limited our analysis to the students from the districts' single middle school (seventh and eighth grades, $n=786$, participation rate $=$ $83 \%$ ), because the sixth- and ninth-grade school structures differed meaningfully from that of middle school. By focusing on only students in the middle school, we held constant potential school-level variables. In addition, as mentioned earlier, considerable research points to the salience of our belief-based constructs in early adolescence and in middle school. The study was conducted in an ethnically and socioeconomically diverse district: 63.4\% European American, 26.4\% African American, 5.9\% Hispanic, and $4.2 \%$ Asian American. The middle school was located in an urban, residential, and commercial community adjacent to a medium-sized postindustrial city on the East Coast. The school maintained a typical high school preparatory curriculum. Informed written consent was obtained from all participants and their parents. Schools were compensated for their participation, and students were given small gifts. The study was approved by the Yale University Human Subjects Committee.

The sample was evenly split by gender ( 386 boys and 400 girls) and was representative of the diversity of the student population. Student's selfreports of their ethnicity indicated 64\% European American, 17\% African American, 6\% Hispanic American, and 13\% other ethnicity. School records and grade reports indicated that $12 \%$ of the sample received special services for mild to moderate special needs.

\section{Measures}

The questionnaires were administered in a group setting in the classroom under the direction of a well-trained graduate student and an undergraduate assistant. All self-report measures were collected during four 40-min sessions separated by 3 to 5 days in mid-October to early November of 1999. All measures reflected general beliefs held around the time of measurement.

To assess motivational style, we used the Motivational Self-Regulation scale from the Multi-CAM (Little \& Wanner, 1997). The Motivational Self-Regulation scale of the Multi-CAM is based on Ryan and Connell's (1989) Reasons Survey and, to a lesser extent, on approach-avoidance concepts forwarded by Elliot and Covington (2001). The scale assesses four of the motivational self-regulatory styles: (a) Intrinsic Motivation (e.g., "I learn things in school because I enjoy it"; six items, $\alpha=.88$ ), (b) Identified Motivation (e.g., "I figure out new lessons in school because it is important to do"; eight items, $\alpha=.81$ ), (c) Introjected Motivation (e.g., "I want to show that I can do new lessons better than others"; six items, $\alpha=.83$ ), (d) Extrinsic Motivation (e.g., "I try to understand new things in school because I want to make my parents happy"; nine items, $\alpha=.85$ ).

To assess personal agency, we used the Agency Beliefs scale of the Multi-CAM (Little \& Wanner, 1997). This scale of the Multi-CAM is based on the Control, Agency, and Means-Ends Inventory (CAMI; Skinner et al., 1988). For this study, we used the two primary dimensions of agency, namely, Agency for Effort (e.g., "When it comes to learning new things in school, I can put in the effort to do it"; six items, $\alpha=.85$ ) and Agency for
Ability (e.g., "When it comes to figuring out a new lesson, I am smart enough to figure it out"; six items, $\alpha=.88$ ).

For the outcome measures, we used teacher-assigned grades in math and English courses that corresponded to the semester that data were collected. These two grades correlated highly with each other $(r=.66 ; p<.001)$. As a measure of school adjustment, we included School Well-Being, which is a six-item scale based on Harter's (1988b) Self-Perception Profile. Sample items are as follows: "I feel comfortable at school" and "I like to be at school" (six items, $\alpha=$.69). This measure is a critical member of our outcomes in that we believe that a student's own well-being at school is in large part a result of intrapersonal orientation to participate in the domain, as reflected by salient belief systems such as agency and motivation. It assesses children's perceptions of how well they feel in the school environment. We also included two general well-being measures, Positive Affect and Negative Affect subscales. The affect scales come from the I FEEL inventory (Dill \& Little, 2003; Little \& Wanner, 1997), which is based on the affect scales of Watson, Clark, and Tellegen (1988). Sample items for Positive Affect include "In the last 2 weeks, I have felt happy" and "In the last 2 weeks, I have felt great" ( 24 items, $\alpha=.95$ ) and for Negative Affect include "In the last 2 weeks, I have felt bad" and "In the last 2 weeks, I have felt sad" ( 24 items, $\alpha=.95$ ). This measure is a key outcome because if intrapersonal orientation in the school domain actually carries over to a general sense of well-being, important levers by which to improve the lives of early adolescents in general may be identified. All self-report items were answered on the same 4-point scale: almost never, seldom, often, almost always.

The QUICKRAVEN (Little et al., 2003) was used to control for differences in intellective skill; the measure is based on the original RAVEN (Raven, 1989). The measure requires timed completion of a set of progressively difficult matrices, requiring skills such as shape and pattern recognition, geometrical reasoning, and class membership (36 items, $\alpha=.95$ ). The measure reflects cognitive ability both in terms of processing speed and task complexity. It is widely regarded as a valid measure of intellective skill that corresponds to other measures of IQ and avoids the use of cultural knowledge or language ability. We chose this measure in order to avoid confounds such as socioeconomic status, first language, and other effects of demographic characteristics in our assessment of intellective skill. We use the term intellective skill to refer to the construct because we wish to reinforce the fact that this is not a typical measure of cognitive ability, such as an IQ test or other language- and math-based cognitive developmental tests.

In general, our measures were selected to provide a rich portrayal of students functioning within the school context. These measures reflect diverse vantage points on early adolescent school functioning that when studied simultaneously enable us to test specific hypothesized relations. In this regard, this study is comparable with work by Patrick et al. (1993) in its attempt to characterize a complete and robust system of perceived control, motivation, and affect system in the academic domain. We extend this approach by integrating meaningful school-based outcomes such as grades, school well-being, and affect.

\section{Analytic Procedures}

First, we conducted tests for group differences in the categorical covariates on the averages of the manifest items for a given construct using standard multivariate general lineral model techniques. Next, prior to testing the mediational hypotheses, we conducted a supplementary model verifying the simplex structure of the continuum of the motivational styles (Jöreskog \& Sörbom, 1996).

Second, to test our mediational hypothesis, we used structural equation modeling (SEM) to develop a latent factor model. In addition to the primary constructs of interest, we included self-reported ethnicity, gender, intellective skill, and resource class participation in the model as covariates. Parceled indicators were used in the analysis (Little, Cunningham, 
Shahar, \& Widaman, 2002). We assessed model fit using standard measures of practical fit: the nonnormed fit index (NNFI), the comparative fit index (CFI), and the root-mean-squared error of approximation (RMSEA). We examined any follow-up tests as either nested-model comparisons (i.e., as chi-square difference tests) or as maximum likelihood tests of the significance of a parameter from zero. Modification indices, residuals, and other tolerance statistics were scrutinized to ensure that meaningful estimates were not inadvertently excluded from the model. Nonsignificant effects were removed from the model.

The mediational test was conducted such that motivational beliefs $(\mathrm{Z})$ predicted the agency beliefs for effort and ability (M) which in turn predicted the outcome measures $(\mathrm{Y})$, using structural equation modeling. Additional direct effects of motivational beliefs (Z) on the outcomes (Y) were tested for significance and for any changes to the parameters from the initial hypothesized model (Baron \& Kenny, 1986). In addition, note that the four motivational self-regulation factors were each allowed to covary freely with each other, as were the two agency factors. This step helped to protect against the risk of multicollinearity in endogenous estimates, given the presence of an ordered continuum of motivational beliefs and highly correlated agency beliefs.

Five estimates from covariates were included in the model as predictors of endogenous variables. Gender and ethnicity were represented by a series of dummy-coded variables to estimate the potential interaction of gender and ethnicity. All of the control variables were allowed to covary freely. In addition, separate zero-order correlation matrices of the study variables were reviewed separately for boys and girls. Relevant scholarship suggests that this strategy would enable more salient and parsimonious interpretation of demographic influences, especially when academic-relevant beliefs are concerned (Graham, 2001; Markus \& Kitayama, 1991).

\section{Results}

\section{Descriptive Statistics}

We conducted a series of multivariate analyses of variance (MANOVAs) to assess mean-level differences by gender and ethnicity. We found significant differences for gender on extrinsic, $F(1,784)=9.69, p<.001$, and introjected, $F(1,784)=26.35$, $p<.0001$, motivation, with boys higher than girls on both styles, and agency for effort, $F(1,784)=10.37, p<.001$, with boys higher than girls, and achievement, $F(1,784)=22.59, p<.0001$, with girls higher than boys. Two separate single-factor (ethnicity) mixed-model MANOVAs revealed no significant differences among the ethnic groups on either the agency dimensions or the motivational self-regulatory styles. A single-factor (ethnicity) mixed-model MANOVA revealed significant differences among the ethnic groups on the QUICKRAVEN, $F(3,782)=9.51, p<$ .0001 , and grades, $F(3,782)=32.90, p<.0001$. Specific contrasts showed that European American students differed from African American students on the QUICKRAVEN, $F(1,781)=$ 26.99, $p<.0001$, and that European American students differed from all of the other ethnic groups on achievement (all differences significant at the $p<.0001$ level), with higher scores for the European Americans. Table 1 contains the descriptive statistics for each ethnic group and gender on the measures.

The bivariate correlations among the averaged manifest variables reflected the anticipated relations among the constructs (see Table 2). For example, the two agency constructs are highly correlated, and the simplex structure among the motivation subscales is readily apparent. Sizable correlations among our predictor variables and anticipated outcomes also suggested that our hypothesized relations may be borne out in a structural model. Review of the correlations for these variables for boys and girls separately reflected a highly similar covariational pattern, supporting our decision to model them together with the use of a control variable.

\section{Model Results}

The supplementary analyses of the simplex structure for the motivational self-regulation continuum achieved excellent overall fit, $\chi^{2}(48, N=786)=155.90$, RMSEA $=.054$ (.044l.063), $\mathrm{NNFI}=.98, \mathrm{CFI}=.98$, and relative fit against the measurement model, $\chi^{2}(51, N=786)=201.38$, RMSEA $=.061(.0531 .070)$, NNFI $=.97$, CFI $=.97$. This model demonstrates that the four motivational styles are distinct constructs that are ordered along the intrinsic pole to the extrinsic pole (Ryan \& Connell, 1989). We note that a confirmatory simplex model of the latent structure is the ideal method to evaluate the plausibility of an ordered continuum (Jöreskog \& Sörbom, 1996).

The primary results of interest are shown graphically in Figure 1. Other estimated effects such as the covariate influences are described in text. The model reflected excellent overall fit, $\chi^{2}(642$, $N=786)=1,221.30$, RMSEA $=.034(.0311 .037), \mathrm{NNFI}=.96$,

Table 1

Demographic Characteristics

\begin{tabular}{|c|c|c|c|c|c|c|c|c|c|c|c|c|}
\hline \multirow[b]{2}{*}{ Variable } & \multicolumn{2}{|c|}{$\begin{array}{c}\text { Girls } \\
(n=400)\end{array}$} & \multicolumn{2}{|c|}{$\begin{array}{c}\text { Boys } \\
(n=386)\end{array}$} & \multicolumn{2}{|c|}{$\begin{array}{c}\text { African } \\
\text { American } \\
(n=133)\end{array}$} & \multicolumn{2}{|c|}{$\begin{array}{l}\text { European } \\
\text { American } \\
(n=504)\end{array}$} & \multicolumn{2}{|c|}{$\begin{array}{c}\text { Hispanic } \\
\text { American } \\
(n=47)\end{array}$} & \multicolumn{2}{|c|}{$\begin{array}{c}\text { Other } \\
(n=102)\end{array}$} \\
\hline & $M$ & $S D$ & $M$ & $S D$ & $M$ & $S D$ & $M$ & $S D$ & $M$ & $S D$ & $M$ & $S D$ \\
\hline \multicolumn{13}{|l|}{ Agency } \\
\hline Ability & 2.90 & 0.66 & 3.04 & 0.61 & 2.90 & 0.58 & 2.99 & 0.66 & 2.90 & 0.69 & 3.03 & 0.62 \\
\hline Effort & 3.11 & 0.60 & 3.04 & 0.58 & 2.96 & 0.59 & 3.10 & 0.60 & 3.09 & 0.64 & 3.12 & 0.51 \\
\hline \multicolumn{13}{|l|}{ Motivation } \\
\hline Intrinsic & 2.38 & 0.70 & 2.31 & 0.71 & 2.40 & 0.61 & 2.32 & 0.73 & 2.37 & 0.78 & 2.40 & 0.68 \\
\hline Identified & 2.97 & 0.44 & 2.95 & 0.46 & 2.96 & 0.43 & 2.95 & 0.46 & 2.93 & 0.46 & 2.98 & 0.43 \\
\hline Introjected & 2.06 & 0.54 & 2.27 & 0.60 & 2.21 & 0.56 & 2.16 & 0.58 & 2.05 & 0.63 & 2.15 & 0.57 \\
\hline Extrinsic & 2.20 & 0.51 & 2.31 & 0.51 & 2.25 & 0.48 & 2.26 & 0.51 & 2.19 & 0.58 & 2.24 & 0.57 \\
\hline Intellective skill & 6.60 & 1.39 & 6.44 & 1.46 & 5.96 & 1.38 & 6.68 & 1.42 & 6.27 & 1.10 & 6.56 & 1.51 \\
\hline Achievement & 81.6 & 10.4 & 77.9 & 11.5 & 73.4 & 10.5 & 82.5 & 9.4 & 75.7 & 12.5 & 76.7 & 13.8 \\
\hline
\end{tabular}

Note. The metric for the math and verbal values has been reduced to one decimal point. 


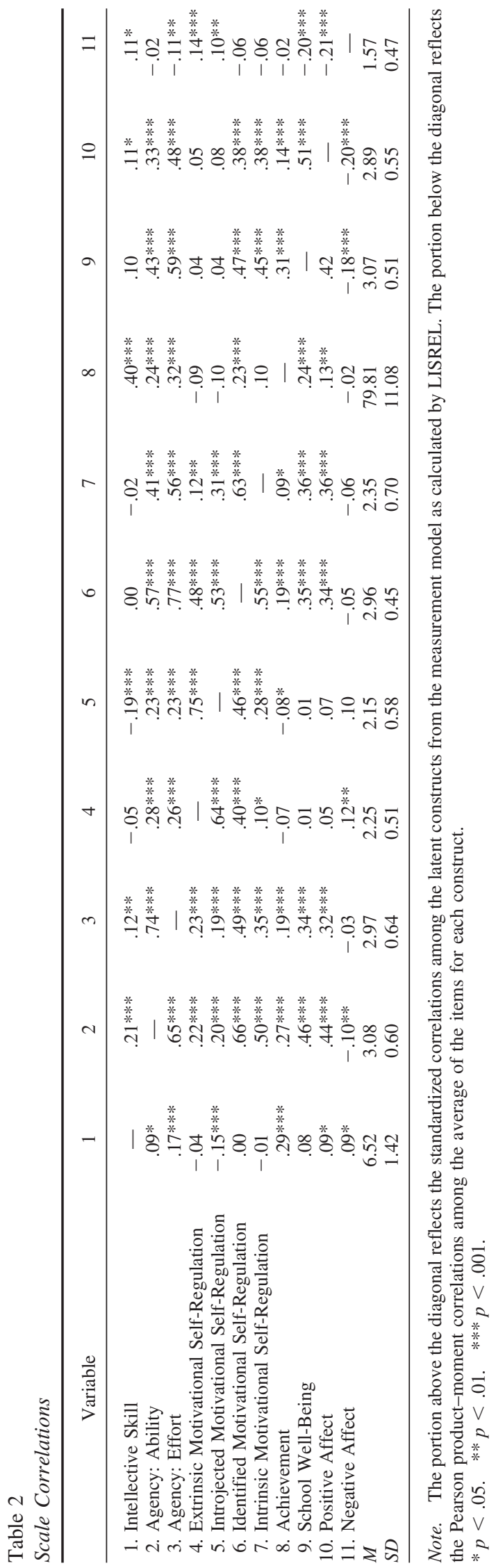

$\mathrm{CFI}=.97$, and relative fit against the measurement model, $\chi^{2}(557$, $N=786)=1,082.88$, RMSEA $=.035(.0321 .038), \mathrm{NNFI}=.96$, $\mathrm{CFI}=.97$. The model was further substantiated by reversing the order of the motivation and agency factors and, as anticipated, substantially lesser mediational effects were observed and somewhat lower model fit was reflected. The correlations, means, and standard deviations for the raw metric scales are shown in Table 2, and the matrix of the actual indicators used in the model can be found at online (see Walls \& Little, 2005). In some cases, the correlations reflected in Table 2 are not reproduced in the structural modeling framework. This change is due to attenuation from other estimates, which is common in SEM when correlated factors are used. For this reason, we anticipated differential prediction of outcomes from factors along the continuum, as outlined in our hypotheses. For this same reason, a change in the direction of the estimates from introjected motivation to the agency factors also occurs between the correlational level statistics and the latent regression parameters in the structural model. Such change is akin to a suppression effect, which we expected. Moreover, this change is not caused by attenuation from control estimates from intellective skill; these estimates remain the same when the covariate effects are removed.

Results supported the hypothesis that agency beliefs pertaining to one's effort (Agency: Effort scale) mediate the relations between motivation and positive school adjustment. Specifically, three of the four motivational self-regulation styles, all except for the extrinsic style, are mediated by agency for effort. As anticipated, the influence of the intrinsic style was only partially mediated, as reflected by its significant direct effects on school wellbeing and positive affect. Also as expected, the extrinsic style had significant direct effects on the outcomes, confirming a detrimental influence on school adjustment. The overall model accounted for $35 \%$ of the variance in grades, $39 \%$ of the variance in school well-being, and $26 \%$ of the variance in positive affect. By contrast, the model accounted for only $4 \%$ of the variance in negative affect.

As mentioned earlier, only the direct and indirect effects of the key constructs are shown in Figure 1. We chose to represent the model in this manner in order to depict the central findings clearly. All remaining estimates included in the model are described here. Covariate effects (standardized) on the school adjustment outcomes were as follows: intellective skill to school grades $(\beta=$ .27), European American ethnicity to school grades (average $\beta$ for boys and girls $=.31$ ), resource class participation to school grades $(\beta=-.13)$, and European American girl status to positive affect $(\beta=.09)$. Sizable effects of covariates on endogenous variables were as follows: intellective skill to introjected motivation $(\beta=$ $-.16)$ and intellective skill to Agency: Ability scale $(\beta=.13)$. Although Figure 1 does not show the correlations among the subconstructs at each phase of the mediation sequence, they were estimated in the final model. After the covariate effects were accounted for, the residual correlations among the motivational constructs remained at the levels shown in Table 2 (i.e., the zero-order relationships). The residual correlation between the two agency constructs dropped from .74 to .73 in the final model. Similarly, the residual correlations among the adjustment measures were also trivially lower than the zero-order relationships.

Overall, the model predicted $26 \%-39 \%$ of the variance across the outcomes. Covariates were substantially related to grades, accounting for approximately $24 \%$ of the variance; the Agency: 


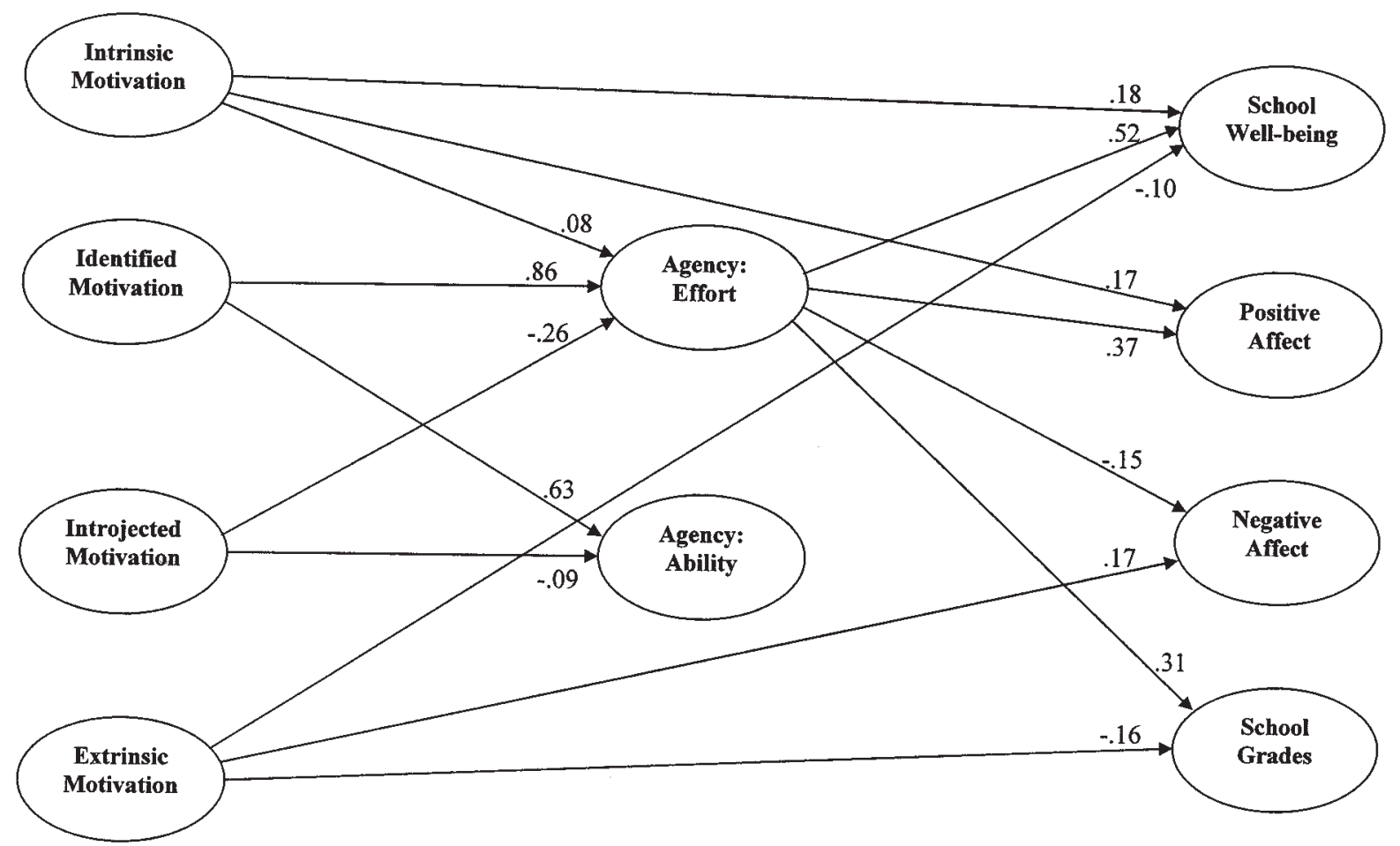

Figure 1. The structural model relating motive-control beliefs to adjustment. Model fit: $\chi^{2}(642, N=786)=$ $1,221.30, p=.00$, root-mean-square error of approximation $=.034(.0311 .037)$, nonnormed fit index $=.96$, comparative fit index $=.97$.

Effort scale and extrinsic motivation accounted for $12 \%$. We also conducted the analysis using second-semester grades and year-end grades; no meaningful differences in the model were revealed.

\section{Discussion}

Our results show clearly that early adolescents' agency beliefs and motivational self-regulation styles have strong, differential, and conjoint effects on school adjustment. If students place faith in their own efforts, rather than their abilities, they indoctrinate a characteristic that is likely to bolster school adjustment substantially beyond the enhancement afforded by motivation alone. However, the styles of motivational self-regulation vary in their influence on agentic beliefs about effort and thereby school adjustment. Among these, identified self-regulation is the most facilitative of positive school adjustment outcomes, intrinsic regulation is somewhat facilitative, whereas introjected regulation is comparatively detrimental. In addition, amid the other self-regulatory styles, extrinsic self-regulation relates to disadvantageous school adjustment, independent of agency views. This result confirms views presented by Ryan, Stiller, and Lynch (1994) that reward-based instructional systems are likely to be antithetical to learning goals.

Not only do the effects support our hypotheses about the system of motive-control beliefs that predicts school adjustment but substantial amounts of variance were accounted for on all of the school adjustment indicators (26\%-39\%). Our study substantially furthers understanding of school adjustment outcomes by characterizing a full system of specifically interrelated predictors whose combined effects are pronounced. In general, our findings demonstrate that when subscales reflect diverse subcomponent beliefs about one's motivation in school and these beliefs are assessed in a model with related beliefs about how one functions in school, a meaningful multivariate system can be identified. This pattern suggests that certain combinations of beliefs relate differentially to levels of success in three important school adjustment outcomes: achievement, school well-being, and affect. These relations are present even with extensive controls for demographic and personologic (i.e., having to do with the individual) characteristics. For these adolescents, such a motive-control belief system may form the framework within which students operate to pursue important life tasks during and following this stage of life.

These findings are also of key importance in integrating theoretical positions on motivational and agentic beliefs. They provide strong support for the contention that beliefs about the reasons for taking part in school activities work in combination with beliefs about how one can exert control over these activities. The combination of motive and control beliefs represents more fully the systemic relations among the factors that promote school adjustment during early adolescence than either set of beliefs considered alone.

A few comments about the effects of covariates in our model are warranted. The advantage in school adjustment outcomes, particularly in school grades, that was traceable to both intellective skill and European American ethnicity was sizable. The fact that the motivation and agency estimates maintained with these simulta- 
neous estimates indicates that its effect on the outcomes is robust and of key importance. At the same time, this finding suggests that more studies of the multivariate influence of beliefs relating to school adjustment outcomes for specific ethnic groups and varying levels of intellectual ability are needed.

\section{Limitations of the Study}

The study results are subject to several limitations inherent to the study design and data available for analysis. First, a convenience sample from one middle school in one school district was used. Hence, the results may be restricted in generalizability to similar communities and school structures. On the other hand, because the participation rate was very high, this study is unique in its ability to characterize the motive-control beliefs and school adjustment of nearly an entire large middle school. Second, we did not have any specific markers of the socioeconomic or life status of the students, although many of our covariates are likely to be proxies of socioeconomic status. Third, the study design cannot establish whether the source of at least some of the variance accounted for on grades may be on the dependent side of the model. That is, teacher grades may be biased toward students who put forth more effort or emphasize the values of effort more than those who emphasize ability as key factors in their work.

Fourth, alternative orderings of the constructs could be supported both theoretically and empirically. This inevitable limitation of the SEM stems from the fact that we have conducted these analyses on a cross-sectional basis. For example, a leading theory offered by Weiner (1995) suggests that attributional locus produces both affect and expectancy, which can combine to produce motivation, followed by action. This theory suggests a countervailing conceptual ordering of the constructs. However, we believe that any ordering will be circumspect until our research designs and analyses can establish reciprocal causation over time. Specifically, intensive longitudinal studies (e.g., weekly or daily assessments over a semester or year) designed specifically to tap into the dynamic interplay among the motive-belief system and school outcomes are needed (Stone \& Shiffman, 1994; Verma, Sharma, \& Larson, 2002; Walls \& Schafer, in press). Related dynamical analyses may provide a useful framework for exploring these relations. Comments in Weiner (1985) regarding the moment to moment variation in causal effects are consistent with this possibility. Current scholarship (Cole \& Maxwell, 2003; Pearl, 2000; Shipley, 2003) reflects considerable debate over the interpretation of cross-sectional SEM while attempting to disentangle fundamental issues of causation in this domain of analysis. As mentioned, extensive longitudinal databases and analyses are needed to definitively establish the system of influences that may exist among these factors and the extent to which interpretation of crosssectional results should inform longitudinal analyses is currently under question. Moreover, these influences may be reciprocal and may exist on multiple time scales and at multiple levels of abstraction. On the other hand, if multiple cross-sectional databases reflect similar factor structures and reproduce hypothesized relations in a given domain, it is likely that these relations must reflect key aspects of the overall system at work across persons. In our study, because we have controlled for key individual characteristics, we believe that the model does present a viable preliminary portrayal of a motivational and control-based belief system in the school context. We look forward to additional studies in which we hope to replicate these findings and extend our analyses longitudinally, with attention to the potential operation of reciprocal relations.

\section{Implications}

The main implications of the study are that the joint role of motivational self-regulation and agency warrants special attention in future theoretical and empirical investigations of school adjustment in adolescence and in interventions designed to enhance school adjustment in middle school students. In particular, the study provides parsimonious explanation of the effects on school adjustment outcomes, one that highlights the importance of discrete and interactive subbeliefs of motivation and personal agency in early adolescence. In order to establish the functioning of this motive-control system more definitively, one needs a controlled study design in which some kind of manipulation of the system in pursued. Additionally, replications of the current study in similar and diverse samples need to be undertaken as well as analyses of longitudinal analyses sensitive to reciprocal relations.

Because our sample was comprised of students from a large typical U.S. middle school, there may be broad application potential from our findings. The nexus of identified regulation and beliefs about one's effort and its strong influence on school adjustment also bolsters the argument for efforts aimed at these school adjustment-related beliefs as a locus for intervention. The results also suggest that considering adolescents' views about their abilities, frequently the target of self-esteem-based interventions, may be a less salient belief area than their views about their potential use of effort. Unfortunately, typical middle schools often contain structures that do not take full advantage of individual differences in academic motivation (Wigfield, Midgley, Reuman, MacIver, \& Fledhaufer, 1993). Schools may be able to use motivation and agency-related diagnostic tools and to pursue the development of related programmatic content in efforts aimed at enhancing school adjustment. At the same time, such intervention should be undertaken thoughtfully, with the recognition that the causal relations over time among these beliefs and actual performance have not yet been established.

\section{References}

Bandura, A. (1977). Self-efficacy: Toward a unified theory of behavioral change. Psychological Review, 84, 191-215.

Baron, R. M., \& Kenny, D. A. (1986). The moderator-mediator variable distinction in social psychological research: Conceptual, strategic, and statistical considerations. Journal of Personality and Social Psychology, 51, 1173-1182.

Boesch, E. E. (1991). Symbolic action theory and cultural psychology. New York: Springer-Verlag.

Brandtstädter, J. (1998). Action perspectives on human development. In W. Damon (Series Ed.) \& R. M. Lerner (Vol. Ed.), Handbook of child psychology: Vol. 1. Theoretical models of human development (5th ed., pp. 807-863). New York: Wiley.

Chapman, M. (1984). Intentional action as a paradigm for developmental psychology: A symposium. Human Development, 27, 113-144.

Cole, D., \& Maxwell, S. (2003). Testing mediational models with longitudinal data: Questions and tips in the use of structural equation modeling. Journal of Abnormal Psychology, 112, 558-577.

Covington, M. V., \& Müeller, K. J. (2001). Intrinsic versus extrinsic 
motivation: Approach/avoidance reformulation. Educational Psychology Review, 13, 157-175.

Deci, E. L., \& Ryan, R. M. (2000). The "what" and "why" of goal pursuits: Human needs and the determination of behavior. Psychological Inquiry, 11, 227-268.

Diener, E. (1984). Subjective well-being. Psychological Bulletin, 95, 542575.

Dill, E. A., \& Little, T. D. (2003). An extensive validation of a multidimensional measure of internalizing symptoms: The I FEEL. Manuscript submitted for publication.

Dweck, C. S. (1986). Motivational processes affecting learning. American Psychologist, 41, 1040-1048.

Eccles, J. S., Lord, S., \& Roeser, R. W. (1996). Round holes, square pegs, rocky roads, and sore feet: A discussion of stage-environment fit theory applied to families and school. In D. Cicchetti \& S. L. Toth (Eds.), Rochester Symposium on Developmental Psychopathology: Vol. VII. Adolescence: Opportunities and challenges (pp. 47-92). Rochester, NY: University of Rochester Press.

Elliot, A. J., \& Covington, M. V. (2001). Approach and avoidance motivation. Educational Psychology Review, 13, 73-92.

Ford, M. E. (1992). Motivating humans: Goals, emotions, and personal agency beliefs. Newbury Park, CA: Sage.

Gottfried, A. E. (1985). Academic intrinsic motivation in elementary and junior high school students. Journal of Educational Psychology, 77, 631-645.

Gottfried, A. E., Fleming, J. S., \& Gottfried, A. W. (2001). Continuity of academic intrinsic motivation from childhood through late adolescence: A longitudinal study. Journal of Educational Psychology, 93, 3-13.

Graham, S. (2001). Inferences about responsibility and values: Implications for academic motivation. In F. Salili \& C. Chiu (Eds.), Student motivation: The culture and context of learning (pp. 31-59). New York: Plenum Press.

Grob, A., Little, T. D., Wanner, B., Wearing, A. J., \& EURONET. (1996). Adolescents' well-being and perceived control across 14 sociocultural contexts. Journal of Personality and Social Psychology, 71, 785-795.

Harter, S. (1988a). The development of self-representations. In T. D. Yawkey \& J. E. Johnson (Eds.), Integrative processes and socialization: Early to middle childhood (pp. 45-78). Hillsdale, NJ: Erlbaum.

Harter, S. (1988b). The Self-Perception Profile for Adolescents. Denver: University of Colorado.

Heckhausen, H., Schmalt, H.-D., \& Schneider, K. (1979). Achievement motivation in perspective. New York: Academic Press.

Jöreskog, K. G., \& Sörbom, D. (1996). LISREL 8: User's reference guide [Computer software manual]. Chicago: Statistical Software International.

Koestner, R., \& Losier, G. F. (2002). Distinguishing three ways of being internally motivated: A closer look at introjection, identification, and intrinsic motivation. In E. L. Deci \& R. M. Ryan (Eds.), Handbook of self-determination research (pp. 101-121). Rochester, NY: University of Rochester Press.

Kuhl, J. (1982). Action vs. state orientation as a mediator between motivation and action. In W. Hacker, W. Volpert, \& M. von Cranach (Eds.), Cognitive and motivational aspects of action (pp. 67-85). Berlin, Germany: VEB Deutscher Verlag der Wissenschaften.

Lerner, R. M., \& Walls, T. A. (1999). Revisiting individuals as producers of their development: From dynamic interactionism to developmental systems. In J. Brandtstädter \& R. M. Lerner (Eds.), Action and selfdevelopment: Theory and research through the life span (pp. 3-36). Thousand Oaks, CA: Sage.

Little, T. D. (1998). Sociocultural influences on the development of children's action-control beliefs. In J. Heckhausen \& C. S. Dweck (Eds.), Motivation and self-regulation across the life span (pp. 281-315). New York: Cambridge University Press.

Little, T. D. (2002). Agency in development. In W. H. Hartup \& R. K.
Silbereisen (Eds.), Growing points in developmental science: An introduction (pp. 223-240). East Sussex, England: Psychology Press.

Little, T. D., Cunningham, W. A., Shahar, G., \& Widaman, K. F. (2002). To parcel or not to parcel: Exploring the question, weighing the merits. Structural Equation Modeling, 9, 151-173.

Little, T. D., Hawley, P. H., Henrich, C. C., \& Marsland, K. (2002). Three views of the agentic self: A developmental synthesis. In E. L. Deci \& R. M. Ryan (Eds.), Handbook of self-determination research (pp. 177195). Rochester, NY: University of Rochester Press.

Little, T. D., \& Lopez, D. F. (1996). Children's action-control beliefs and emotional regulation in the social domain. Developmental Psychology, 32, 299-312.

Little, T. D., Lopez, D. F., Oettingen, G. O., \& Baltes, P. B. (2001). A comparative-longitudinal study of action-control beliefs and school performance: On the role of context. International Journal of Behavioral Development, 25, 237-245.

Little, T. D., Miyashita, T., Karasawa, M., Mashima, M., Oettingen, G., Azuma, H., \& Baltes, P. B. (2003). The links among action-control beliefs, intellective skill, and school performance in Japanese, U.S., and German school children. International Journal of Behavioral Development, 27, 41-48.

Little, T. D., Oettingen, G., Stetsenko, A., \& Baltes, P. B. (1995). Children's action-control beliefs and school performance: How do American children compare with German and Russian children? Journal of Personality and Social Psychology, 69, 686-700.

Little, T. D., \& Wanner, B. (1997). The Multi-CAM: A multidimensional instrument to assess children's action-control motives, beliefs, and behaviors. Berlin, Germany: Max Planck Institute for Human Development.

Markus, H., \& Kitayama, S. (1991). Culture and the self: Implications for cognition. Psychological Review, 98, 224-253.

Patrick, B. C., Skinner, E. A., \& Connell, J. P. (1993). What motivates children's behavior and emotion? Joint effects of perceived control and autonomy in the academic domain. Journal of Personality and Social Psychology, 65, 781-791.

Pearl, J. (2000). Causality: Models, reasoning and inference. New York: Cambridge University Press.

Raven, J. (1989). The Raven Progressive Matrices: A review of national norming studies and ethnic and socioeconomic variation within the United States. Journal of Educational Measurement, 26, 1-16.

Roeser, R. W., Eccles, J. S., \& Sameroff, A. J. (1998). Academic and emotional functioning in early adolescence: Longitudinal relations, patterns, and prediction by experience in middle school. Development and Psychopathology, 10, 321-352.

Ryan, R. M., \& Connell, J. P. (1989). Perceived locus of causality and internalization: Examining reasons for acting in two domains. Journal of Personality and Social Psychology, 57, 749-761.

Ryan, R. M., \& Deci, E. L. (2000). Self-determination theory and the facilitation of intrinsic motivation, social development, and well-being. American Psychologist, 55, 68-78.

Ryan, R. M., Sheldon, K. M., Kasser, T., \& Deci, E. L. (1996). All goals are not created equal: An organismic perspective on the nature of goals and their regulation. In P. M. Gollwitzer \& J. A. Bargh (Eds.), The psychology of action: Linking cognition and motivation to behavior (pp. 7-26). New York: Guilford Press.

Ryan, R. M., Stiller, J. D., \& Lynch, J. H. (1994). Representations of relationships to teachers, parents, and friends as predictors of academic motivation and self-esteem. Journal of Early Adolescence, 14, 226-249.

Schunk, D. H. (1991). Goal setting and self-evaluation: A social cognitive perspective on self-regulation. In M. L. Maehr \& P. R. Pintrich (Eds.), Advances in motivation and achievement: Vol. 7. Goals and selfregulatory processes (pp. 85-113). Greenwich, CT: JAI Press.

Shipley, B. (2003). From biological hypotheses to structural equation models: The imperfection of causal translation. In B. H. Pugesek, A. Tomer, \& A. von Eye (Eds.), Structural equation modeling: Applica- 
tions in ecological and evolutionary biology (pp. 194-211). New York: Cambridge University Press.

Skinner, E. A. (1990). Age differences in the dimensions of perceived control during middle childhood: Implications for developmental conceptualizations and research. Child Development, 61, 1882-1890.

Skinner, E. A. (1995). Perceived control, motivation, and coping. Beverly Hills, CA: Sage.

Skinner, E. A. (1996). A guide to constructs of control. Journal of Personality and Social Psychology, 71, 549-570.

Skinner, E. A., Chapman, M., \& Baltes, P. B. (1988). The control, agency, and means-ends beliefs interview. Berlin, Germany: Max Planck Institute for Human Development and Education.

Skinner, E. A., Wellborn, J. G., \& Connell, J. P. (1990). What it takes to do well in school and whether I've got it: The role of perceived control in children's engagement and school achievement. Journal of Educational Psychology, 82, 22-32.

Skinner, E. A., Zimmer-Gembeck, M. J., \& Connell, J. P. (1998). Individual differences and the development of perceived control. Monographs of the Society for Research in Child Development, 63(2/3, Serial No. 254).

Stetsenko, A., Little, T. D., Oettingen, G., \& Baltes, P. B. (1995). Agency, control and means-ends beliefs about school performance in Moscow children: How similar are they to beliefs of Western children? Developmental Psychology, 31, 285-299.

Stipek, D. (1996). Motivation and instruction. In R. C. Calfee \& D. C. Berliner (Eds.), Handbook of educational psychology (pp. 85-113). New York: Macmillan.

Stone, A. A., \& Shiffman, S. (1994). Ecological momentary assessment (EMA) in behavioral medicine [Special issue]. Annals of Behavioral Medicine, 16(3).

Verma, S., Sharma, D., \& Larson, R. W. (2002). School stress in India:
Effects on time and daily emotions. International Journal of Behavioral Development, 26, 500-508.

Walls, T. A. (2002). Relations among agency beliefs, motivational selfregulation, and academic performance in adolescence. Unpublished doctoral dissertation, Boston College.

Walls, T. A., \& Little, T. D. (2005). Summary statistics of adjustment model indicators. Retrieved January 11, 2005, from Pennsylvania State University University Park Campus, Methodology Center Web site: http://methodology.psu.edu/adjustment_indicators.html

Walls, T. A., \& Schafer, J. L. (in press). Models for intensive longitudinal data. New York: Oxford.

Watson, D., Clark, L., \& Tellegen, A. (1988). Development and validation of brief measures of positive and negative affect. Journal of Personality and Social Psychology, 54, 1063-1070.

Weiner, B. (1985). An attributional theory of achievement motivation and emotion. Psychological Review, 92, 548-573.

Weiner, B. (1995). Judgments of responsibility: A foundation for a theory of social conduct. New York: Guilford Press.

Weiner, B., \& Kukla, A. (1970). An attributional analysis of achievement motivation. Journal of Personality and Social Psychology, 15, 1-20.

Wentzel, K. R., Weinberger, D. A., Ford, M. E., \& Feldman, S. S. (1990). Academic achievement in preadolescence: The role of motivational, affective, and self-regulatory processes. Journal of Applied Developmental Psychology, 11, 179-193.

Wigfield, J. S., Midgley, C., Reuman, D., MacIver, D., \& Fledhaufer, H. (1993). Negative effects of traditional middle schools on students' motivation. Elementary School Journal, 93, 553-574.

Received January 22, 2003 Revision received July 2, 2004 Accepted August 13, 2004

\section{E-Mail Notification of Your Latest Issue Online!}

Would you like to know when the next issue of your favorite APA journal will be available online? This service is now available to you. Sign up at http://watson.apa.org/ notify/ and you will be notified by e-mail when issues of interest to you become available! 